\title{
Algumas considerações a partir do processo de padronização da descrição arquivística
}

\section{Acácia Maria Maduro Hagen}

\section{Resumo \\ Considerações sobre o conceito de descrição arquivística e sobre o processo de padronização da descrição. Relações da arquivística com as demais disciplinas da área da ciência da informação, a partir das questões surgidas no processo de padronização da descrição.}

\section{Palavras-chave}

Arquivística; Ciência da informação; Descrição; Padronização.

\section{APRESENTAÇÃO}

A arquivologia no Brasil encontra-se em meio ao processo de construção enquanto ciência. O momento é de refletir sobre a realidade concreta e tentar construir o objeto científico arquivologia. Para isto, o estudo das atividades desenvolvidas nos arquivos é fundamental, ou seja, refletir sobre a prática arquivística procurando analisá-la em todos os seus componentes e ao mesmo tempo relacioná-la às operações semelhantes das áreas de conhecimento chamadas de ciências da informação. Assim, pode-se chegar a descobrir as especificidades do saber arquivístico.

Em função da importância cada vez maior da troca de informações em todos os setores, seja em nível nacional ou internacional, a padronização é um processo que se desenvolve nas mais diversas áreas. A arquivística não é exceção: em nível internacional existe a ISAD(G) (Norma Internacional de Descrição Arquivística Geral), elaborada pelo Conselho Internacional de Arquivos, em fase de avaliação; em vários países são seguidas normas nacionais, como no Canadá, no Reino Unido e nos Estados Unidos.

No Brasil, esta discussão ainda está por ser feita, e pretendemos contribuir para que se desenvolva. Apresentaremos inicialmente algumas considerações sobre o conceito de descrição arquivística e sobre o processo de padronização da descrição. A seguir, trataremos das relações da arquivística com as demais disciplinas da área da ciência da informação, a partir das questões surgidas no processo de padronização da descrição.

\section{A descrição arquivística}

O termo descrição, ao longo dos últimos anos, adquiriu nova acepção dentro da arquivística. Nos livros mais antigos, como o Manual da Associação dos Arquivistas Holandeses, o capítulo dedicado à descrição aborda os procedimentos a serem seguidos para a elaboração dos diversos instrumentos de pesquisa, sem chegar a definir claramente o que seja o processo de descrição ${ }^{1}$. Discutem-se os tipos de instrumentos de pesquisa, seu grau de detalhamento e a importância de serem seguidas regras, tais como o tratamento do acervo como um todo antes de se descrever um fundo ou uma série em particular.

A intenção do texto parece ser a de estabelecer um procedimento propriamente arquivístico, ou seja, um procedimento que se preocupe com o conjunto dos documentos do arquivo, contrapondo-se a uma prática ligada aos historiadores (especialmente aqueles de orientação positivista), que se dedicavam em maior profundidade aos documentos considerados mais importantes.

Esta discussão já estabelecia uma tentativa de normalização, à medida que reivindicava um tratamento descritivo padrão para todos os documentos, sem que critérios externos determinassem a exclusão de qualquer grupo ou peça documental. Somente após a completa descrição do acervo deveriam ser descritos em particular os grupos mais pesquisados ou considerados de interesse maior, sendo a transcrição dos documentos reservada como uma atividade suplementar, e não uma preocupação básica do arquivista. 
Schellenberg, na obra Documentos públicos e privados: arranjo e descrição ${ }^{2}$, também dá destaque à definição dos diferentes tipos de instrumentos de pesquisa, aparentemente partindo-se da idéia de que não há necessidade de se discutir o conceito de descrição, mas esclarecer como devem ser os instrumentos de pesquisa resultantes deste processo.

Lodolini, em um trabalho de 1984, dedica apenas um capítulo à atividade de descrição, sem usar este termo. Ele se refere aos trabalhos de arquivo como sendo "(...) a ordenação e a inventariação, que é conseqüência e conclusão da ordenação."3 Depois de definir como instrumentos de pesquisa fundamentais o guia e o inventário, Lodolini destaca a importância do conhecimento da história institucional:

O inventário é precedido pelo que se indica, resumidamente, como "introdução" ou "prólogo", ou seja, por um estudo sobre a magistratura que produziu os papéis, suas atribuições, estruturas, sobre sua evolução e sobre os reflexos que as atribuições, estruturas, evolução da instituição tiveram no modo de produção dos papéis. ${ }^{4}$

Nos textos brasileiros, encontram-se algumas definições do termo descrição:

A descrição mostra o conteúdo dos fundos recolhidos e se processa através de instrumentos de pesquisa ou meios de busca, que vão do geral para o particular. $^{5}$

A descrição dos conjuntos documentais deve ser feita em relação à sua:

- substância, indicando-se unidade de organização, funções, atividades, operações, assuntos;

- estrutura, indicando-se esquema de classificação adotado, unidades de arquivamento, datas abrangentes, classes ou tipos físicos dos documentos, quantidade. $^{6}$

"Conjunto de procedimentos que, a partir de elementos formais e de conteúdo, permitem a identificação de documentos e a elaboração de instrumentos de pesquisa."
No manual francês de arquivística publicado em 1993, encontram-se referências à alteração recente de significado do termo descrição. Michel Duchein coloca:

Em inglês (e, portanto, em muitos países onde a língua inglesa tem influência) utiliza-se o termo description para designar a elaboração de instrumentos de pesquisa. Em francês não existe um termo completamente equivalente (inventariação, catalogação, todos têm um sentido mais restrito e específico). Talvez o termo description termine por se aclimatar na arquivística francesa em seu sentido anglo-saxão. ${ }^{8}$

No capítulo dedicado às operações de classificação e descrição, Christine Nougaret também explica a utilização do termo:

A palavra descrição é utilizada aqui não em seu sentido habitual de descrição material - que consiste em fornecer as características físicas do documento descrito -, mas no sentido muito mais amplo dado ao inglês "description", ao espanhol "descripción", ao italiano "descrizione" e ao franco-canadense "description". 9

A seguir, refere-se à normalização, explicando que o trabalho arquivístico não pode ter a rigidez da catalogação bibliográfica, mas pode ser padronizado. Ela aponta os três elementos indispensáveis em qualquer descrição: a identificação do produtor (para assegurar o respeito à proveniência), a descrição das unidades documentais e a indexação (para facilitar a recuperação da informação) ${ }^{10}$.

Para evidenciar a recente evolução do conceito de descrição arquivística, podem-se comparar duas definições, ambas da SAA (Society of American Archivists), mas de períodos diferentes:

1974: O processo de estabelecer controle intelectual sobre o patrimônio documental mediante preparação de instrumentos de pesquisa. ${ }^{11}$

1988: Descrição arquivística é o processo de obter, ordenar, analisar e organizar qualquer informação que sirva para identificar, administrar, localizar e interpretar o patrimônio documental de instituições arquivísticas e explicar os contextos e sistemas de registro dos quais estes documentos foram selecionados. ${ }^{12}$

A principal diferença entre estas duas definições é destacada por Victoria Walch:

A definição do WGSAD afirma que cada vez que um arquivista registra qualquer elemento de informação sobre o acervo de sua instituição, isto é um ato descritivo. Assim, a descrição não apenas abrange a criação de produtos descritivos tradicionais como catálogos e inventários, mas também se estende a outros, criados para atender a uma gama de necessidades arquivísticas, tais como relatórios de avaliação, transferências de propriedade, etiquetas de caixas e pastas e compilações estatísticas. ${ }^{13}$

Outra importante diferença entre as duas definições apresentadas é o fato de na segunda haver uma preocupação com a análise da operação descritiva. Os procedimentos passaram a ser analisados, e não apenas listados, ou seja, procuram-se identificar todas as ações individuais que compõem a atividade descritiva como um todo e estabelecer relações com outras operações semelhantes.

As diversas definições do termo descrição não são arbitrárias, mas estão ligadas a concepções diferentes da atividade arquivística. Heloísa Bellotto, por exemplo, de acordo com a chamada teoria das três idades, coloca uma visão de clara diferenciação entre os arquivos correntes, intermediários e permanentes, reservando a estes últimos a atividade propriamente descritiva:

"A descrição é uma tarefa típica dos arquivos permanentes. Ela não cabe nos arquivos correntes, onde seu correspondente é o estabelecimento dos códigos de assunto; tampouco faz sentido no âmbito dos arquivos intermediários onde a freqüência da utilização secundária é quase nula. Nestes depósitos, para fins de esclarecimento, informações adicionais e testemunho ainda decorrentes do uso primário, os instrumentos de busca resumem-se nas listas de remessas de papéis, nas tabelas de temporalidade 
e nos quadros gerais de constituição de fundos. $O$ assunto, a tipificação das espécies documentais, as datas-baliza, as subscrições, as relações orgânicas entre os documentos, e a ligação entre função e espécie, enfim todos os elementos ligados às informações de interesse do historiador é que serão objeto do trabalho descritivo."14

Já Luís Carlos Lopes, defendendo a proposta de uma arquivística integrada, na qual a teoria das três idades é rediscutida, afirma que a descrição ocorre em todos os momentos do tratamento dos documentos:

"Acredita-se que, dentro da perspectiva da arquivística integrada, a descrição começa no processo de classificação, continua na avaliação e se aprofunda nos instrumentos de busca mais específicos. Em todos os casos, o trabalho do arquivista é representar ideologicamente as informações contidas nos documentos. As operações de natureza intelectual são, sem exceção, de natureza descritiva. Portanto, é difícil separar a descrição das duas outras atividades fundamentais da prática arquivística."15

Para melhor compreender esta questão, deve-se lembrar que nos países como o Canadá, Estados Unidos e Reino Unido, os documentos correspondentes à fase de arquivos correntes e intermediários são administrados por records managers, sendo considerados propriamente arquivos apenas os documentos de guarda permanente, administrados pelos archivists. Assim, quando se fala em descrição arquivística já está se falando implicitamente em documentos de guarda permanente.

Mesmo concordando com Lopes no aspecto de que todas as operações intelectuais são de natureza descritiva, acreditamos ser necessária uma distinção entre o tipo de descrição num arquivo permanente e num arquivo corrente. No arquivo permanente, a descrição tem como objetivo permitir a pesquisa, ou seja, está voltada para um público mais amplo e diversificado, e deve trazer mais elementos informativos sobre os documentos. No arquivo corrente não são necessárias todas estas informações, pois o usuário já tem conhecimento da estrutura da organi- zação produtora dos documentos, de suas funções, enfim, de muitos dos dados que a descrição feita no arquivo permanente deve trazer.

Uma visão abrangente da descrição arquivística é dada por Michael Cook, em seu livro Information management and archival data. Segundo este autor, a descrição tem como base a teoria da representação:

A teoria da representação é a de que enquanto os arquivos originais devem ser necessariamente armazenados na estante numa determinada ordem e localização física (normalmente em embalagens fechadas), as representações dos originais podem ser multiplicadas e armazenadas em qualquer ordem e em qualquer lugar que seja considerado útil. ${ }^{16}$

As representações têm duas características que os originais não têm:

- podem ser distribuídas para fora do arquivo para atender aos usuários, ou seja, podem tornar-se públicas através da forma impressa ou da comunicação por computadores, por exemplo;

- podem ser organizadas internamente de forma a facilitar a busca de informações pelos usuários. ${ }^{17}$

Tendo estas funções em mente, o conceito de instrumentos de pesquisa torna-se mais flexível, pois reconhece-se que para cada necessidade pode-se elaborar um instrumento diferente. Não há sentido, deste ponto de vista, em discutir exaustivamente os conceitos de inventário, catálogo etc. Recomendase apenas que exista um instrumento principal que descreva a ordem estrutural do acervo, para registrar e explicar o sistema que lhe deu origem, ou seja, que esclareça o respeito à proveniência. Outra recomendação importante é que os instrumentos de pesquisa sejam concebidos como um sistema, com referências cruzadas e pontos de acesso estabelecidos.

O conceito de pontos de acesso vem da biblioteconomia, e é fundamental para o estabelecimento das normas da descrição arquivística. Pontos de acesso são os nomes ou termos através dos quais se pode recuperar a informação sobre um livro, no caso da biblioteconomia, ou sobre os registros descritos do ponto de vista arquivístico. Para os livros, utilizam-se elementos como o nome do autor, o título ou assunto; para os documentos de arquivo, o mais evidente é o nome da pessoa ou instituição produtora, de acordo com o princípio do respeito à proveniência. Os pontos de acesso, para serem efetivos, devem submeter-se às regras de vocabulário controlado, ou seja, devem ser padronizados.

Este aspecto será retomado a seguir, na discussão da relação da arquivística com as demais ciências da informação. Antes disso, apresentaremos um histórico do processo de padronização da descrição

\section{O processo de padronização da descrição arquivística}

O Grupo de Trabalho em Padronização da Descrição Arquivística da SAA (Society of American Archivists), a partir da literatura sobre o assunto, dividiu os padrões em três níveis:

- Padrões técnicos, os mais rígidos, que levam à produção de resultados idênticos;

- Convenções (também chamadas de "regras" ou "padrões profissionais"), mais flexíveis, acomodando algumas variações em sua aplicação;

- Orientações ("guidelines"), que fornecem um conjunto amplo de critérios para orientar uma prática. ${ }^{18}$

Os padrões em arquivística são apenas dos dois últimos tipos, não havendo definições que se apliquem sem adaptação a qualquer arquivo. As primeiras tentativas de padronização na área foram os dicionários de termos técnicos, tanto os elaborados pelos organismos internacionais como os dicionários nacionais.

A descrição está sendo objeto de esforços de padronização basicamente em função do impacto das novas tecnologias, em especial os computadores, que possibilitaram a troca de informações por meio de redes nacionais e internacionais. Para se beneficiar destes recursos, a comunidade arquivísti- 
ca teve de desenvolver o aspecto de comunicação do conhecimento, até então não especialmente desenvolvido. Este processo de discussão em torno da padronização da descrição, ao envolver conceitos utilizados especialmente pela biblioteconomia e pela documentação, também leva à discussão do próprio conceito de arquivística, à reafirmação de sua especificidade e suas relações com as disciplinas próximas. Abordaremos esta questão a seguir, após um breve histórico do processo de estabelecimento dos padrões na descrição arquivística.

\section{Histórico}

Em 1989, o Conselho Internacional de Arquivos (CIA) promoveu uma reunião de especialistas para traçar os planos de criação de uma norma descritiva internacional. Em outubro de 1990, houve a primeira reunião plenária da Comissão Ad Hoc sobre Normas de Descrição Arquivística, na Alemanha (Hör-Grenzhause), quando se formou um subgrupo encarregado de escrever uma proposta de regras gerais. Após reunir-se em Liverpool, em julho de 1991, o subgrupo apresentou um texto na reunião plenária realizada em Madri, em janeiro de 1992. O documento produzido em Madri, com o título de ISAD(G) (Norma Internacional Geral de Descrição Arquivística) foi divulgado para a comunidade arquivística e apresentado durante o XII Congresso Internacional de Arquivos, em Montreal, em setembro de 1992, sendo discutido em uma sessão aberta. A Comissão voltou a se reunir em janeiro de $1993 \mathrm{em}$ Estocolmo, para reavaliar o texto após as várias sugestões recebidas no processo de discussão. O texto final está atualmente em avaliação e deverá ser publicado em 1999. ${ }^{19}$

Mesmo após várias revisões, ainda restam muitos pontos que são criticados por membros da comunidade arquivística. Antonia Heredia, por exemplo, aponta a falta de atenção para os arquivos correntes:

"Considero que a descrição, como tarefa, deve ser obrigatória também num arquivo central, e ao sujeitar-se a regras desde o início suporá o início da fluidez descritiva que se sucederá nos depósitos sucessivos dos documentos, facilitando a representação definitiva. Ou será que se pretende uma descrição para os arquivos correntes e outra para os históricos, que é do que se trata nesta norma? ${ }^{20 "}$

Um dos integrantes do grupo que redigiu a norma $\operatorname{ISAD}(G)$, em um seminário realizado em 1993, reconheceu várias limitações do trabalho, esclarecendo que a Comissão havia feito algumas escolhas, tendo em vista tornar sua tarefa realizável. Em relação às diversas fases dos arquivos, ele esclarece:

1. Estamos tratando com arquivos que já foram transferidos para um depósito e arranjados e que também estão, ou estarão, em breve, disponíveis à inspeção do público. Em conseqüência, não nos preocupamos (talvez devêssemos dizer ainda) com os arquivos correntes ou semicorrentes que não foram transferidos mas que não estão disponíveis para consulta. Certamente reconhecemos que estes arquivos também precisão de descrição e controle, mas não nossa primeira prioridade. ${ }^{21}$

Nos diversos países, as situações são muito variadas:

Em âmbito nacional o grau de normalização e os métodos empregados variam muito de um país para outro; assim, na China, Noruega e a ex-União Soviética existem normas nacionais concretas, na Suécia exerce-se um certo controle através da legislação arquivística, em outros casos como os da França e da Itália os arquivos nacionais são os encarregados de promulgá-las; onde não existe uma direção central de arquivos, como na Grã-Bretanha e nos Estados Unidos, são os organismos profissionais que têm procurado desenvolvê-las. ${ }^{22}$

No Reino Unido surgiu a primeira norma nacional de descrição. Estabeleceuse um Projeto Nacional de Descrição, desenvolvido na Universidade de Liverpool com a participação da Society of Archivists e sob a direção de Michael Cook. Como resultado deste projeto, foi publicado em 1986 o Manual of Archival Description (MAD), que teve uma segunda edição revista em 1990 $(\mathrm{MAD} 2)^{23}$, e é utilizado como referência desde então. O que se estabelece no manual são normas para descrição destinadas à elaboração de instrumentos de pesquisa, não sendo dirigido especificamente para a troca de informações.

Nos Estados Unidos, pelo contrário, o processo de normalização teve início impulsionado pela criação de bancos de dados bibliográficos, despertando os arquivistas para as possibilidades de participar em redes para a troca de informações. Em 1977, a SAA (Society of American Archivists) criou um grupo para estudar a possibilidade de os arquivos virem a integrar um sistema nacional de informação (NISTF-National Information Systems Task Force). A primeira conclusão do grupo é que seria necessário criar um padrão para a troca de informações arquivísticas e que o mais simples e econômico seria adaptar o padrão bibliográfico MARC (Machine Readable Cataloging), já amplamente utilizado. Assim, surgiu em 1982 o padrão MARC AMC (MARC Format for Archival and Manuscripts Control), formalmente uma propriedade conjunta da SAA e da Biblioteca do Congresso, ou seja, unindo as instituições responsáveis pelas normas técnicas de arquivos e bibliotecas dos Estados Unidos. ${ }^{24}$

Além do padrão MARC AMC, voltado para a forma da descrição, existe nos Estados Unidos o padrão de conteúdo, estabelecido em Archives, Personal Papers and Manuscripts $-2^{\text {nd }}$. ed. ${ }^{25}$

A importância e a quantidade de normas utilizadas na descrição arquivística nos Estados Unidos pode ser demonstrada pela publicação de um livro: Standards for archival description ${ }^{26}$. Publicado em 1994, sob a responsabilidade da SAA, o livro descreve 86 normas utilizadas na descrição arquivística, fazendo referência a outras 157, consideradas de importância secundária.

O Canadá é outro país que tem normas de descrição específicas. A discussão está sendo conduzida pelo Bureau of Canadian Archivists e pelo Conselho Canadense de Arquivos, e desde 1992 estão sendo publicados capítulos, à medida que são completados. O primeiro capítulo trata das regras gerais de descrição, e os demais abordam aspectos específicos. 
O mais recente desenvolvimento das normas internacionais foi a publicação da ISAAR(CPF), International Standard Archival Authority Record for Corporate Bodies, Persons and Families, preparada pelo mesmo grupo responsável pela $\operatorname{ISAD}(\mathrm{G})$.

A norma ISAAR(CPF) coloca uma questão que ainda deve ser muito discutida pela comunidade arquivística: a necessidade de se elaborar vocabulários controlados, sendo os termos utilizados como pontos de acesso para o pesquisador. O objetivo da norma é assegurar que haja uma lista controlada com os nomes das instituições, pessoas e famílias produtoras de arquivos, ou seja, assegurar que não sejam utilizados diversos nomes ao mesmo tempo para a mesma entidade, dificultando 0 acesso do pesquisador que faz uma busca. Além do nome, a norma também estrutura um campo com dados contextuais: localização, área geográfica de atuação, nacionalidade, situação legal, área de atuação, atribuições, estrutura administrativa, relações com outras pessoas, famílias ou instituições, entre outros (para cada um dos tipos de entidade descrita, aplica-se um conjunto de informações específico). ${ }^{27}$

Ao introduzir a questão do vocabulário controlado, bastante desenvolvida na biblioteconomia, a norma ISAAR(CPF) acende ainda mais a discussão das semelhanças e diferenças entre as diversas disciplinas da área das ciências da informação, já presente desde as primeiras tentativas de normalização.

\section{A arquivística e as ciências da informação}

Michel Duchein, abordando a questão da importância crescente dos computadores e do impulso dado à padronização da descrição arquivística pelo uso das novas tecnologias, aponta o que considera um problema:

O risco, indo-se muito longe nesta direção, será de ver a "descrição" arquivística alinhar-se pura e simplesmente aos conceitos da biblioteconomia ou da documentação, em detrimento dos princípios de base da arquivística. ${ }^{28}$
Para avaliar até que ponto existe este risco, deve-se voltar a uma questão básica: o que é a arquivística? Se tivermos claramente estabelecidos os elementos que definem a arquivística enquanto campo específico do conhecimento, poderemos diferenciá-la da biblioteconomia e da documentação.

Luís Carlos Lopes procura avançar no aspecto teórico, apresentando alguns pressupostos a partir dos quais se poderia construir uma teoria da informação para uso geral e especificamente de interesse para o conhecimento arquivístico. Entre estes pressupostos, podemos citar:

"2. Os atos humanos de qualquer natureza produzem informações.

3. A informação é uma categoria abstrata que se materializa quando é registrada e representa uma sucessão de atos ou fragmentos que possam ser definidos como fatos.

5. Quanto mais único e isolado for o registro da informação, mais ele será parcial, fragmentário e de difícil cognoscibilidade.

6. Quanto mais plural e correlacionado for o registro da informação, mais integral e possível de ser interpretado.

10. Considera-se documento todo e qualquer suporte material a que possa ser atribuído, de modo arbitrário, científico ou não, a existência de um conteúdo informacional."29

O objeto da arquivística seriam os arquivos, definidos como

"acervos compostos por informações orgânicas originais, contidas em documentos (...) produzidos ou recebidos por pessoa física ou jurídica, decorrentes do desenvolvimento de suas atividades, sejam elas de caráter administrativo, técnico ou científico, independentemente de suas idades e valores intrínsecos." 30
Desta forma, a arquivística não se confundiria com as demais ciências da informação mesmo que haja uma aparente semelhança em algumas questões, como no caso da padronização da descrição para fins de participação em bancos de dados bibliográficos. O enfoque da arquivística sempre é a informação registrada no conjunto dos documentos, nunca perdendo de vista o princípio fundamental do respeito à proveniência, ou seja, a importância de deixar evidente o contexto em que os documentos foram produzidos ou recebidos.

Outro aspecto importante na questão da padronização da descrição arquivística é a relação necessária com as outras operações: avaliação e arranjo. Tomando um conceito amplo de descrição, ela ocorre em todas as fases de tratamento de um acervo documental, e vai refletir em sua forma mais elaborada, os instrumentos de pesquisa, o resultado das operações anteriores. A descrição, padronizada ou não, sempre é uma concretização do princípio do respeito à proveniência, pois assim deve ter sido feito o arranjo dos documentos.

Em relação às semelhanças e diferenças entre o controle bibliográfico e arquivístico, Richard Smiraglia apresenta um quadro. As semelhanças seriam as seguintes: objetivos comuns aos catálogos bibliográficos e instrumentos de pesquisa arquivísticos (exploração do conhecimento registrado), dicotomia descritiva básica entre elementos físicos e intelectuais e o dilema comum da busca de informação, onde quem faz o instrumento dispõe de dados de que o pesquisador não dispõe. As diferenças seriam: diferenças físicas e intelectuais entre livros e documentos de arquivo (livros são preparados para serem descritos e divulgados, sendo unidades com título, autor e assunto definidos, enquanto os arquivos são resultado de uma atividade, sendo conjuntos de documentos que não podem ser definidos por um assunto ou autor) e diferenças no tipo de informação que os pesquisadores buscam (como conseqüência das características já citadas, a busca de informação bibliográfica é em geral mais específica do que a arquivística, baseada principalmente em informações contextuais, e não em documentos específicos). ${ }^{31}$ 
Rousseau e Couture, por sua vez, colocam a necessidade da arquivística estabelecer, através da pesquisa, o seu campo específico de atuação, ao lado da biblioteconomia, da informática e das ciências da informação, libertando-se da dependência da história e da administração. ${ }^{32}$

Para encerrar, vejamos a posição de um autor que, reconhecendo a especificidade da arquivística, aponta a necessidade de o arquivista dominar alguns recursos da área do gerenciamento da informação e do corpo teórico da ciência da informação:

Nem toda a teoria e nem todas as técnicas desenvolvidas pelos cientistas da informação são necessariamente aplicáveis ao trabalho dos records managers $^{33}$ ou arquivistas. Algumas partes deste corpo de conhecimento, entretanto, são essenciais. As áreas de conhecimento mais relevantes são as seguintes:

- conhecimento básico em teoria das comunicações e da informação;

- conhecimento básico de computação;

- técnicas de recuperação da informação, especialmente regras de catalogação e teoria e prática de classificação, uso de autoridades, teoria e prática de pesquisa informatizada de bancos de dados e textos;
- análise das necessidades dos usuários;

- provisão de serviços para o usuário. ${ }^{34}$

Esta proposta de aproximação da arquivística às demais disciplinas ligadas à informação parece-nos promissora, na medida em que abre o campo de atuação do arquivista, permitindo a utilização de recursos já desenvolvidos por outros profissionais. Os arquivistas podem dedicar-se às suas atividades específicas, aproveitando os esforços já realizados em outras áreas e participando de um trabalho conjunto com benefícios gerais.

Neste movimento de aproximação às outras disciplinas, fica também mais claro o que é específico da arquivística. O processo de elaboração de normas e padrões descritivos é lento exatamente por causa do elemento fundamental da abordagem arquivística, ou seja, a preocupação com a ordem original dos documentos. $O$ trabalho do arquivista tem algo de arqueológico, na medida em que procura reconstituir a entidade que originou o conjunto documental a ser trabalhado, determinando sua estrutura e seu funcionamento a partir dos indícios dados pela própria documentação e por fontes externas. Aprofundando-se nas questões específicas de cada arquivo, muitas vezes torna-se difícil para o arquivista enquadrar-se a normas e padrões de descrição. Outra característica do trabalho arquivístico é a idéia de abrir ao máximo as possibilidades de pesquisa do usuário, apresentando-Ihe os documentos com explicações quanto ao momento e às condições de sua produção, sem dirigir a pesquisa com a indicação de assuntos. As demais disciplinas do campo, pelo contrário, procuram identificar para o usuário os assuntos, dirigem a pesquisa exatamente para os pontos específicos pelos quais o usuário faz sua busca. Tendo-se em vista estas duas questões, pode-se entender por que o processo de padronização da descrição arquivística tem se desenvolvido no sentido de uma estrutura comum de descrição, e não tanto no de um conteúdo padronizado. A elaboração de linguagens controladas, algo novo na arquivologia, começou exatamente pelos nomes das pessoas e instituições produtoras dos arquivos, ou seja, por um elemento de identificação, que não depende tanto de uma escolha do arquivista.

O processo de padronização da descrição arquivística está em andamento, tanto em nível internacional quanto em nosso país. O limite da padronização ainda está por ser estabelecido, mas acreditamos que a característica mais importante deste processo é o fato de provocar a discussão a respeito da atividade arquivística, a respeito do que seja o saber arquivístico, de suas especificidades e pontos de aproximação às demais disciplinas do campo da ciência da informação. 


\section{REFERÊNCIAS BIBLIOGRÁFICAS}

1. ASSOCIAÇÃO DOS ARQUIVISTAS HOLANDESES. Manual de arranjo e descrição de arquivos. 2a ed. Rio de Janeiro : Arquivo Nacional, 1973.

2. BELLOTTO, Heloísa Liberalli. Arquivos permanentes: tratamento documental. São Paulo: T.A. Queiroz, 1991.

3. CAMARGO, Ana Maria de Almeida \& BELLOTTO, Heloísa Liberalli (coords.). Dicionário de terminologia arquivística. São Paulo : Associação dos Arquivistas Brasileiros - Núcleo Regional de São Paulo : Secretaria de Estado da Cultura, 1996.

4. CASTRO, Astréa de Moraes e; CASTRO, Andresa de Moraes e; GASPARIAN, Danuza M.C. Arquivística = técnica; arquivologia = ciência. Brasília : ABDF, 1985.

5. COOK, Michael \& PROCTER, Margareth. $A$ MAD user guide. Aldershot: Gower, 1989.

6. COOK, Michael. Information management and archival data. London : Library Association Publishing, 1993.

7. CRUZ MUNDET, José Ramón. Manual de archivística. Madri : Fundación Germán Sánchez Ruipérez : Pirámide, 1994.

8. FAVIER, Jean \& NEIRINCK, Danièle (orgs.) La pratique archivistique française. Paris : Archives Nationales, 1993.

9. HENSEN, Steven L. (comp.) Archives, Personal Papers and Manuscripts; A cataloguing manual for archival repositories, historical societies and manuscript libraries. 2 nd ed. Chicago : Society of American Archivists, 1989.

\section{Considerations arising from the process of standardization of archival description}

\section{Abstract}

Considerations on the concept of archival description and the process of standardization of archival description. Relations among archivology and the other disciplines of information science area, starting from questions arising from this process.

\section{Keywords}

Archivology; Information science; Description; Standardization.
10. HEREDIA HERRERA, Antonia. Observaciones sobre la norma ISAD(G). Na Internet, URL: http://www.pi.cnr.it/S.Miniato/rivista/herrera.html.

11. ISAD(G): norma geral internacional de descrição arquivística, adotada pela Comissão ad hoc de Normas de Descrição, Estocolmo, Suécia, 21-23 de janeiro de 1993, versão final aprovada pelo CIA. $2 a$ ed. rev. Rio de Janeiro : Arquivo Nacional, 1998. (Publicações técnicas, 48)

12. KITCHING, Christopher. Nuevas direcciones en esfuerzos internacionales. In: SEMINARIO SOBRE NORMAS INTERNACIONALES PARA DESCRIPCION ARCHIVISTICA. México, 1993. Actas... Washigton, 1994.

13. LODOLINI, Elio. Archivística: principios y problemas. Madrid : ANABAD, 1993.

14. LOPES, Luis Carlos. A informação e os arquivos : teorias e práticas. Niterói : EDUFF ; São Carlos (SP) : EDUFSCar, 1996.

15. PAES, Marilena Leite. Arquivo; teoria e prática. 2a ed. Rio de Janeiro : Fundação Getúlio Vargas, 1991.

16. ROUSSEAU, Jean-Yves \& COUTURE, Carol. Les fondements de la discipline archivistique. Québec : Université du Québec, 1994.

17. RUIZ RODRíGUES, Antonio Ángel (ed.). Manual de archivística. Madrid : Síntesis, s.d.

18. SCHELLENBERG, Theodore Roosevelt. Documentos públicos e privados: arranjo e descrição. 2a ed. Rio de Janeiro : Fundação Getúlio Vargas, 1980.

19. SMIRAGLIA, Richard P. (ed.) Describing archival materials; the use of the MARC AMC format. New York : Haworth, 1990.

20. WALCH, Victoria Irons \& MATTERS, Marion (comp.) Standards for archival description; a Handbook. Chicago : Society of American Archivists, 1994.

\section{Acácia Maria Maduro Hagen}

Licenciada em História e Mestre em Sociologia Rural pela Universidade Federal do Rio Grande do Sul, Historiógrafa coordenadora do Núcleo de Acervo do MARGS (Museu de Arte do Rio Grande do Sul Ado Malagoli).

E-mail: amhagen@portoweb.com.br 